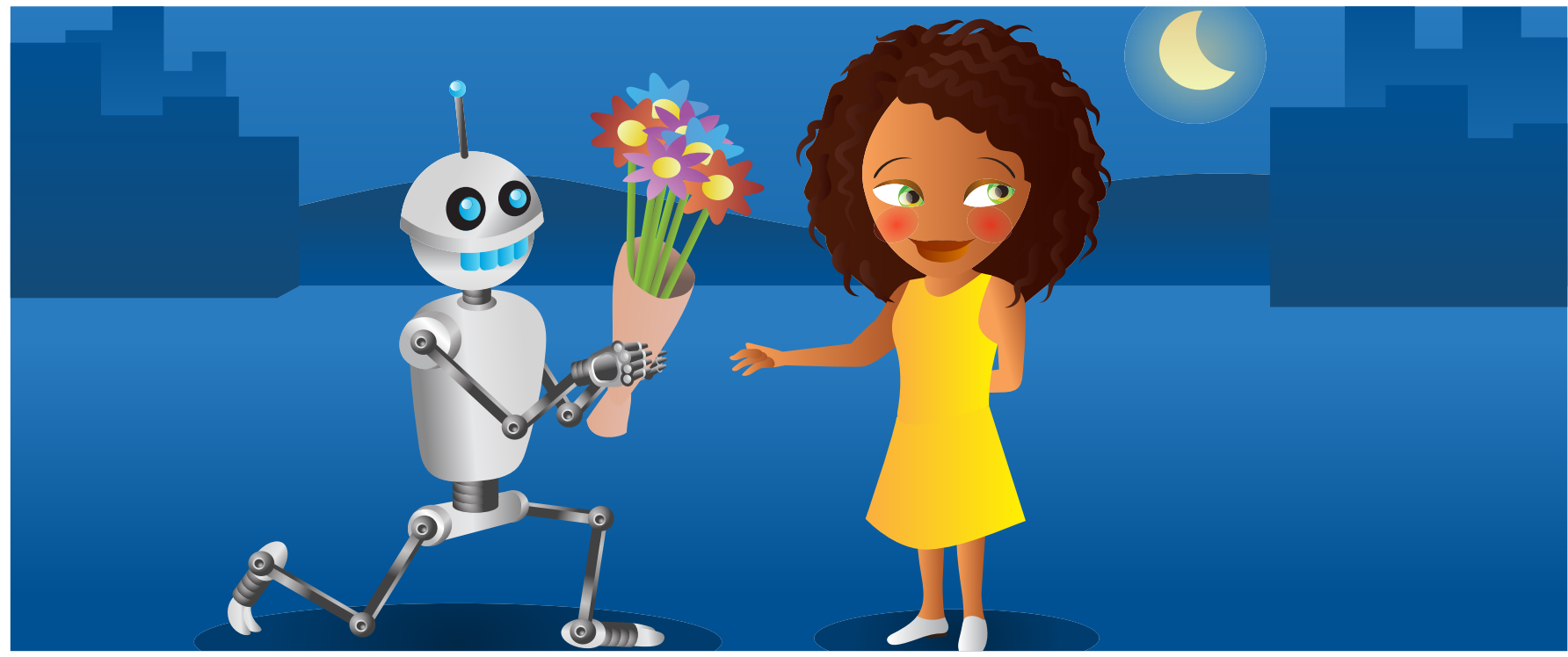

\title{
TRAINING YOUR EMOTIONAL BRAIN: FROM SCIENCE FICTION TO NEUROSCIENCE
}

\section{Patricia Bado ${ }^{1,2 *}$, Maria Stewart ${ }^{1}$ and Jorge Moll ${ }^{1,2}$}

${ }^{1}$ Cognitive Neuroscience and Neuroinformatics Unit, D'Or Institute for Research and Education (IDOR),

Rio de Janeiro, Brazil, ${ }^{2}$ Programa de Ciências Morfológicas, Instituto de Ciências Biomédicas, Universidade Federal do

Rio de Janeiro, Rio de Janeiro, Brazil

\section{REVIEWED BY:}

ST. ANDREW'S COLLEGE 12-15 YEARS OLD
Neuroscience is an interdisciplinary field (psychology, biology, physics, and chemistry), which aims to study the nervous system including the brain. Our neuroscience research project begins with a science fiction story: in the future, androids (robots made of flesh and bones) become virtually identical to humans, except that they lack deep emotions, such as empathy (the ability to understand what others are feeling). What if, in real life, we could find a way to tell if someone was having empathic feelings just by measuring brain activity? And, even more, what if people could boost their feelings of love, tenderness, or affection using information from their own brain activity? This was our goal - to make people change their own brain function while receiving information about their brains. We asked 24 volunteers to enter in a magnetic resonance imaging scanner that measures brain activity. Inside the machine, they were asked to think about important people in their lives while looking at their own brain activity on a monitor - a process called "neurofeedback." The volunteers receiving this feedback were able to increase the activity of their brain activity that 


\section{EMPATHY}

The ability to understand and feel what another person is experiencing.

\section{NEUROIMAGING}

Techniques to either directly or indirectly image the structure and function of the nervous system.

\section{NEUROFEEDBACK}

A computer-aided method that uses real-time displays of brain activity via monitor and/or loudspeaker. The brain activity is shown to participants, and through this real-time feedback, they can learn to self-regulate their brains.

\section{MAGNETIC}

RESONANCE IMAGING (MRI)

A scanner that measures brain activity related to the level of oxygen in the blood. is associated with empathy. This evidence tells us that maybe people can change their brain's emotional states and increase their feelings of empathy.

Technologies from science fiction movies and books sometimes become true in real life. Our research project was inspired by a Sci-Fi story from a book by Philip K. Dick called "Do Androids Dream of Electric Sheep" (1968), which was later turned into a movie called "Blade Runner" (1982). The story takes place in the year 2019, when androids made of artificial flesh, bones, and brains became so similar to humans that they could hardly be recognized as "machines." A detection device had to be used to find the only difference between androids and humans: the fact that only humans could have deep emotions, truly care for someone else, and experience what the other person is feeling - something we call empathy.

Empathic emotions such as affection are very important for humans, since the ability to build and sustain connections to other people is critical for our wellbeing and survival [1]. These empathic emotions are important for things such as loving relationships, the care of a mother for her children, team spirit, and cooperation, or even something as simple as helping a friend. These emotions also lead to behaviors, such as unselfishness, that help people to live together in society [2]. Therefore, just like in the Sci-Fi story, these empathic emotions are an important part of what makes us human. Previous studies have demonstrated that specific regions of the brain are important for these emotions [3].

Neuroscience is the scientific study of the nervous system: what it does, its structure, and how it develops. As neuroscientists who are deeply interested in investigating brain function and its connection to human behavior, we asked ourselves: "what if, in real life, we could find out a way to "read" empathic feelings by measuring the activity of people's brains in real time?" Inspired by recent neuroscience studies in which images of the brain were examined (called neuroimaging studies), while people tried to change their own brain function, we further asked: "what if a person could increase their empathic feelings using information from their own brain activity?" This technique is called neurofeedback. Feedback is data that tell you how well you are doing with a particular task. In this case, we call it "neurofeedback" because the feedback is coming from the brain and the participants are using knowledge of their own brain signal to modify the brain's activity.

To study this, we recruited 24 people from local universities and research labs. These people were placed in a magnetic resonance imaging (MRI) scanner that measures brain activity using the level of oxygen in the blood (Figure 1). The general principle of this technique, called functional MRI, goes like this: when we use a part of our brain to, for example, 


\section{FIGURE}

An MRI machine in an experimental setting.

The image shows the participant being prepared by the experimenter to enter the MRI machine, where he will try to modulate his own brain activity.

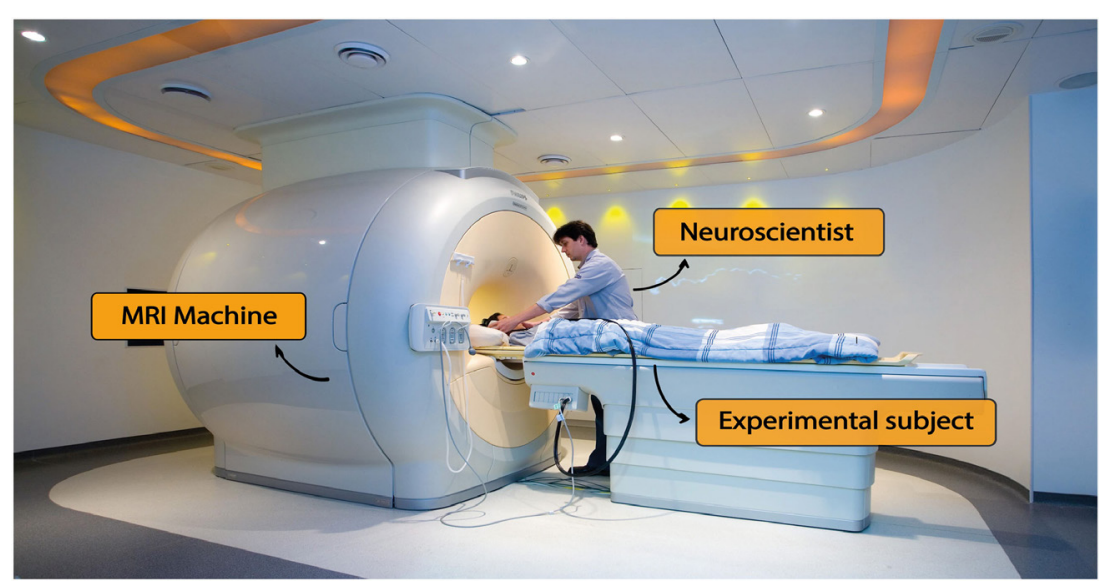

FIGURE

move our hand or think about a loved one, more blood with high oxygen content is recruited to the specific part of the brain that contributes to that function. Based on this principle, scientists can use an MRI scanner to show which part of the brain is activated when a certain task is being performed.

Inside the MRI machine, participants were told to think about happy memories involving people they love (family or friends) and to feel warm feelings such as affection and tenderness. The experiment was divided in training and feedback sessions: during training, participants should only think about their loved ones; after training session, the participants did the same thing, but this time, while they thought about happy, loving memories and warm feelings, they also looked at a computer screen that gave the participants neurofeedback - the screen showed them pictures that represented their brain activity. These pictures told them whether or not their brain activity was the same as it was the training session. In this experiment, the neurofeedback pictures consisted of ring-like shapes that varied in smoothness, from smooth rings to jagged/bumpy rings (see Figure 2). The smoother the ring shape the participants saw as they felt the empathic feelings, the closer their brain activity matched the activity they had the first time they were in the MRI, without neurofeedback. If the ring was "bumpy," it meant that they were not feeling these warm feelings as clearly as they did first time. So, if they saw a bumpy ring, the participants could try harder to feel the warm feelings, and if they were successful in doing so, the ring would smooth out.

In case you are wondering the reason we choose a ring shape was to avoid using images that could influence brain activity all by themselves. For instance, if we showed feedback images of people, complex scenes, or even basic colors, these pictures alone could activate emotional areas of the brain, complicating the experiment. 


\section{FIGURE 2}

Visual cues used as feedback. The image shows feedback rings with different amounts of "bumpiness" according to the measured brain activity. A perfect ring shape (bottom right) represents the clearest brain pattern achieved by the participant, while the bumpiest ring shape (upper left) represents a less clear brain pattern associated with empathic feelings.
CONTROL GROUP

Participants not affected by experimental manipulation (in this case, the neurofeedback), thereby serving only as a comparison group.
FIGURE 2

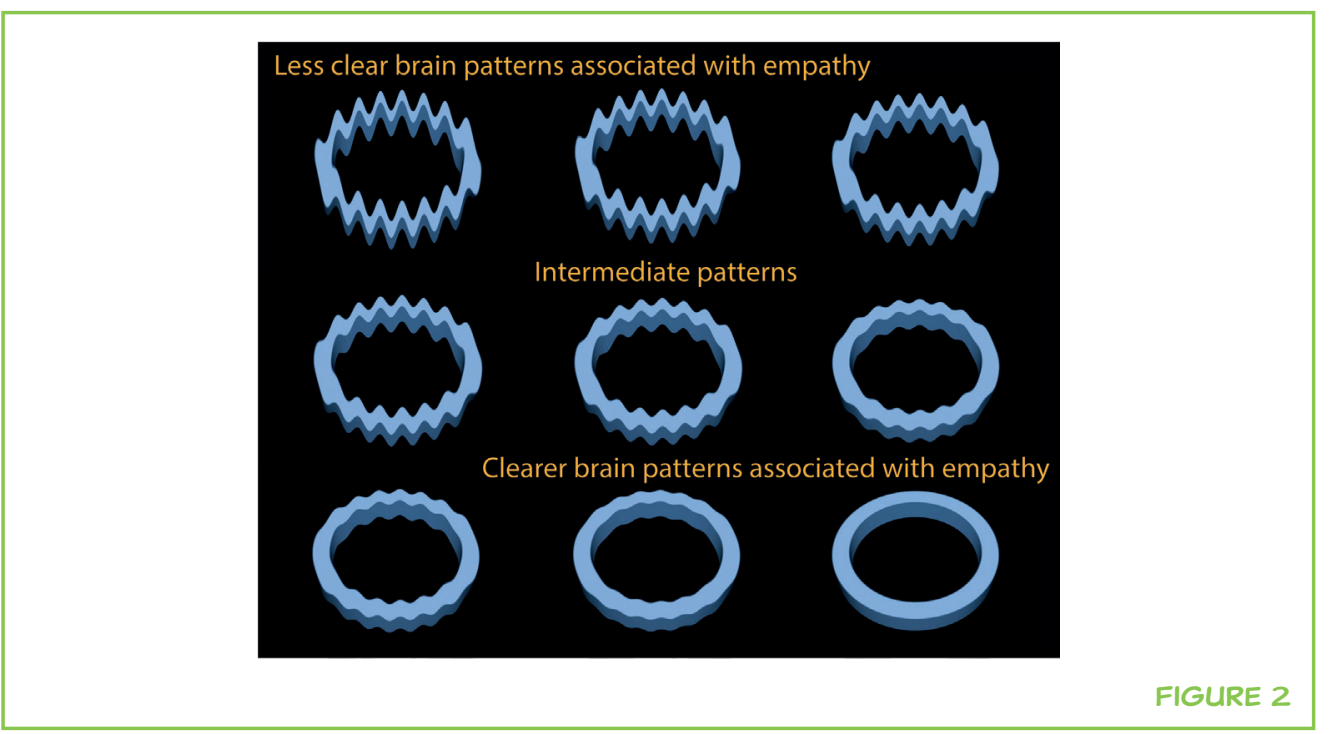

\section{BACK TO OUR EXPERIMENT}

In scientific research, we always need what we call a "control group" to make sure that the effects we are measuring are really caused by the experiment we are doing and are not just random. To make sure our results were not just random, we assigned our participants to one of two different groups: one group that received the real neurofeedback on their brain activity described above (the neurofeedback group) and the other that was shown pictures of randomly changing rings that actually had nothing to do with their brain activity (the control group). These control participants did not know that there was a separate neurofeedback group, and they were told that the rings were displayed on the screen just to help them focus on the screen and keep their eyes open.

We had another control group, too. In this control, the participants were asked to think about memories in which they felt strong positive feelings of achievement and pride in the presence of other people (e.g., winning a swimming competition). This control was important to check whether our results were actually specific for the empathic emotions or whether they were true for positive emotions in general.

So far so good. But what finally happened to the participants' brains at the end of their "brain training"? Those who saw their own brain activity reflected by the shapes of the rings displayed on the screen and then changed this activity by working to increase their empathic feelings (neurofeedback group) were able to actually increase these feelings, showing more consistent brain patterns associated with these emotions than the control group. More precisely, the feedback group increased brain activity patterns associated with empathy. The brain regions that these participants were able to activate when feeling these empathic emotions included two areas with complicated names: the frontopolar cortex and 


\section{FIGURE 3}

Brain regions with increased activation after feedback training. The image demonstrates that two areas of the brain, the septohypothalamic area and the frontopolar cortex (orange-black arrows) have increased activation after brain training. This increase in activation was only observed in the feedback group, not in the control groups.

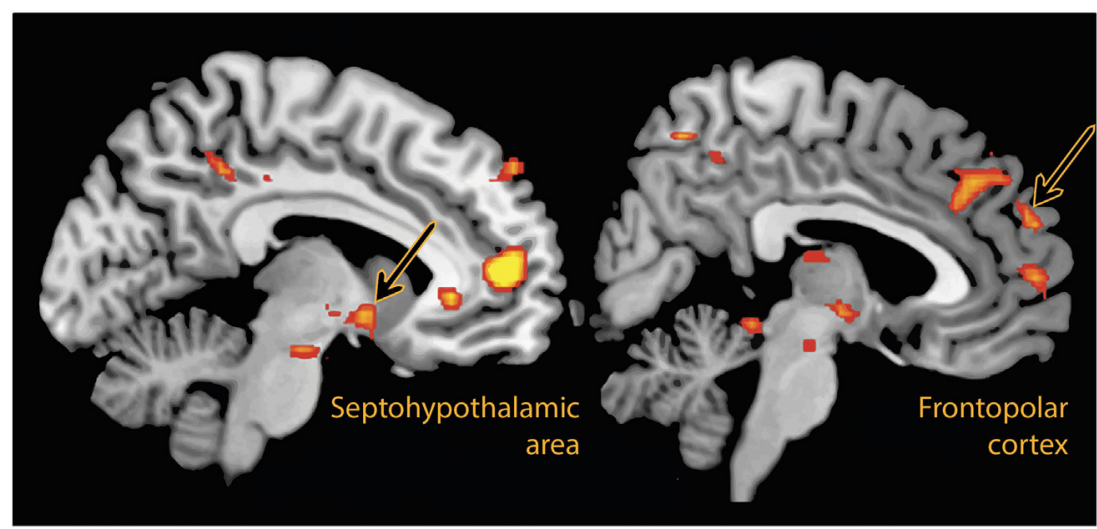

FIGURE 3

the septohypothalamic area (Figure 3). These regions have been previously linked to positive, empathic emotions. Participants in the control group, on the other hand, failed to improve their brain patterns associated with empathy. We also found that the increased activation in these two brain regions was specific for the empathic emotions and did not happen in the pride memories.

Besides, just by using the brain activation patterns on the computer screen, we were also able to tell how the emotional states they were imagining (tenderness/ empathy or pride) at any given time point. This sounds very much like the "brain reading" that is seen in some science fiction movies! But, in this case, we are able to "brain read" a very specific and complex emotional state, tender/empathic feeling. Because we had two emotional conditions to choose from - empathy and pride - a blind guess of the correct brain state would be equivalent to the chance of guessing whether a flipped coin would turn up heads or tails, giving us a one in two chances of getting it right (50\%). Our result in this experiment was a 75\% rate of correctly classifying the brain state, meaning whether the participants were feeling tenderness or pride. This is an awesome result, we think!

In summary, our study demonstrates that people can use information about their own brain activity related to empathy to change their own brain's emotional states, which has important applications in real life. Perhaps in the near future, it will be possible to train people to feel empathy in order to improve human relationships and to promote more kindness among people. Who knows?

\section{ORIGINAL SOURCE ARTICLE}

Moll J., Weingartner JH., Bado P., Basilio R., Sato JR., et al. 2014. Voluntary enhancement of neural signatures of affiliative emotion using fmri neurofeedback. PLoS ONE 9(5):e97343. doi:10.1371/journal.pone.0097343 


\section{REFERENCES}

1. Insel, T. R., and Young, L. J. 2001. The neurobiology of attachment. Nat. Rev. Neurosci. 2(2):129-36. doi:10.1038/35053579

2. Moll, J., de Oliveira-Souza, R., Garrido, G. J., Bramati, I. E., Caparelli-Daquer, E. M., Paiva, M. L., et al. 2007. The self as a moral agent: linking the neural bases of social agency and moral sensitivity. Soc. Neurosci. 2(3-4):336-52. doi:10.1080/17470910701392024

3. Moll, J., Bado, P., de Oliveira-Souza, R., Bramati, I. E., Lima, D. O., Paiva, F. F., et al. 2012. A neural signature of affiliative emotion in the human septohypothalamic area. J. Neurosci. 32(36):12499-505. doi:10.1523/JNEUROSCI.6508-11.2012

SUBMITTED: 04 November 2015; ACCEPTED: 02 September 2016; PUBLISHED ONLINE: 23 September 2016.

EDITED BY: Lesley K. Fellows, McGill University, Canada

CITATION: Bado P, Stewart M and Moll J (2016) Training Your Emotional Brain: From Science Fiction to Neuroscience. Front. Young Minds 4:21. doi:10.3389/frym.2016.00021

CONFLICT OF INTEREST STATEMENT: The authors declare that the research was conducted in the absence of any commercial or financial relationships that could be construed as a potential conflict of interest.

COPYRIGHT @ 2016 Bado, Stewart and Moll. This is an open-access article distributed under the terms of the Creative Commons Attribution License (CC BY). The use, distribution and reproduction in other forums is permitted, provided the original author(s) or licensor are credited and that the original publication in this journal is cited, in accordance with accepted academic practice. No use, distribution or reproduction is permitted which does not comply with these terms.

\section{REVIEWED BY}

\section{ST. ANDREW'S COLLEGE, 12-15 YEARS OLD}

Our school is a large coeducational school in Dublin, Ireland. We all study general science as part of a broad curriculum for 12- to 15-year olds.

\section{AUTHORS}

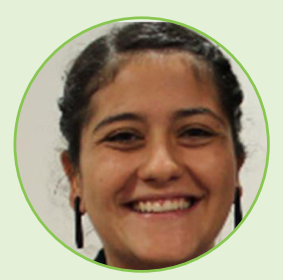

\section{PATRICIA BADO}

I am a PhD student from Federal University of Rio de Janeiro and D'Or Institute for Research and Education. My research is mostly focused on human behavior and neuroimaging. My current PhD project aims to comprehend the representation of motivations in the brain using neuroimaging and behavioral measures. Apart from research, I like samba music and hiking around Rio de Janeiro. *bado.patricia@gmail.com 


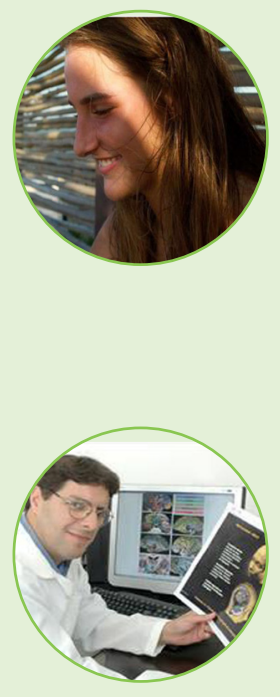

\section{MARIA STEWART}

My name is Maria Stewart and I am a neuroscience lover! I am currently doing an internship at D'Or Institute that gave me this opportunity to collaborate with Frontiers for Young Minds. I am also a psychology student at PUC Rio, and I intend to explore my passion for both neuroscience and psychology, and hopefully contribute to the field of science! Until then, I will stick with my other passions: studying, sports such as surfing and tennis, and, of course, the delightful Brazilian beaches.

\section{JORGE MOLL}

I graduated from medical school, at the Federal University of Rio de Janeiro (UFRJ), Brazil (1994) and did my neurology residency at the same university (1997). I then obtained a PhD in Experimental Pathophysiology, at the Faculty of Medicine, University of Sao Paulo (2003) and spent 3 years as a post-doctorate research fellow at the National Institutes of Health, NINDS, Cognitive Neuroscience Section, Bethesda, USA (2004-2007). Currently, I run the Cognitive and Behavioral Neuroscience Unit and the D'Or Institute for Research and Education in Rio de Janeiro, Brazil. I am a lover of science, music, and Sci-Fi. 